\title{
Levetiracetam-Associated Acute Kidney Injury and Drug Reaction with Eosinophilia and Systemic Symptoms (DRESS) Syndrome
}

\author{
Mathieu Leblanc ${ }^{1}$, Martin Plaisance ${ }^{2 *}$ \\ ${ }^{1}$ Internal Medecine Residency Program, Faculté de Médecine et des Sciences de la santé, Université de \\ Sherbrooke, Sherbrooke, Canada \\ ${ }^{2}$ Nephrology Division, Department of Medicine, Centre Hospitalier Universitaire de Sherbrooke, \\ Sherbrooke, Canada \\ Email: ${ }^{*}$ Martin.Plaisance@Sherbrooke.ca
}

Received 17 November 2014; revised 16 December 2014; accepted 23 December 2014

Copyright (C) 2014 by authors and Scientific Research Publishing Inc.

This work is licensed under the Creative Commons Attribution International License (CC BY).

http://creativecommons.org/licenses/by/4.0/

(c) (i) Open Access

\begin{abstract}
DRESS syndrome is a severe drug induced reaction. Acute kidney injury (AKI) is sometimes present in the form of an acute interstitial nephritis. We present the case of a 75 -year-old man with glioblastoma who developed a DRESS two months after starting levetiracetam and a few days after stopping dexamethasone. His skin and kidneys improved after removing levetiracetam and introducing again corticosteroids. DRESS has been reported more frequently with other antiepileptics, rarely with levetiracetam. Clinicians should add this drug to the list of potential causes of AKI.
\end{abstract}

\section{Keywords}

\section{Acute Kidney Injury, DRESS Syndrome, HSV-1, Levetiracetam}

\section{Background}

Drug reaction with eosinophilia and systemic symptoms (DRESS) syndrome is a rare and potential fatal disease that usually follows introduction of a drug. Antiepileptics are the predominant agents reported [1]. The reaction produces nonspecific constitutional symptoms including fever, lymphadenopathy and malaise, as well as symptoms related to organ involvement, the liver being the organ most commonly affected. 10 to 30 percent of DRESS syndromes include an acute interstitial nephritis [2]. Allopurinol is the drug most often associated with renal involvement, but cases linked to phenytoin, dapsone, penicillin, nonsteroidal anti-inflammatory drug (NSAID)

\footnotetext{
${ }^{*}$ Corresponding author.
} 
and other drugs have been reported [2]. Cases of DRESS syndrome secondary to levetiracetam have been described in the literature [3] [4] but, to our knowledge, none with renal involvement. Two cases of acute interstitial nephritis not in the setting of DRESS have been reported [5]. Herein, we report a new case of DRESS syndrome with acute kidney injury, most probably an acute interstitial nephritis secondary to levetiracetam.

\section{Case Report}

A 75-year-old man was started on levetiracetam $500 \mathrm{mg}$ twice a day October $3^{\text {rd }}, 2013$ for partial seizures following a neurosurgical procedure to remove a glioblastoma, done August $28^{\text {th }}, 2013$. Dexamethasone $4 \mathrm{mg}$ twice a day had also been prescribed three days before the operation. Ezetimibe was the only other medication taken by the patient. He had no history of heart disease. He had been taking it for several years for dyslipidemia. It was stopped on admission January $9^{\text {th }}$, 2014. No NSAID had been taken in the months prior to the events. He had not received chemotherapy, only radiotherapy.

Dexamethasone was slowly tapered and discontinued on December $15^{\text {th }}$, 2013. In the following days, the patient developed malaise, fatigue and a generalize pruritic maculopapular rash on his trunk, proximal limbs and his face. He never accused chest pain or shortness of breath. Levetiracetam was switched to phenytoin December $31^{\text {st }}$. At that time, his temperature was $38.2^{\circ} \mathrm{C}$, his serum creatinine level had increased from $75 \mu \mathrm{mol} / \mathrm{L}$ (day of the surgery) to $108 \mu \mathrm{mol} / \mathrm{L}$. Four days later, his symptoms worsened and his creatinine level raised to 139 $\mu \mathrm{mol} / \mathrm{L}$. Vancomycin and clindamycin were tried for a few days. On January $9^{\text {th }}$, his creatinine level was 465 $\mu \mathrm{mol} / \mathrm{L}$. He never had low blood pressure which on average was 125/75. He did not have invasive arterial procedure or contrast. It was his first acute kidney injury. Cervical lymphadenopathy and numerous buccal aphthous ulcers were new findings at the physical exam. The most notable laboratory abnormality was a leucocytosis at 11,000 white blood cells $/ \mathrm{mm}^{3}$ with an important eosinophilia at $4700 \mathrm{~mm}^{3}$. His urinary analysis was normal. Urinary protein/creatinine ratio was minimal at $0.26 \mathrm{~g} / \mathrm{g}$. A renal echography showed hyperechogenic cortex without obstruction. AST and ALT were normal. Viral culture of the buccal ulcers was positive for HHV-1. EBV serology showed past infection. HBV and HCV serologies were negative.

Because DRESS syndrome with severe renal involvement was suspected, a dose of prednisone $50 \mathrm{mg}$ was given without proceeding to a skin or kidney biopsy. The following day, creatinine level was $512 \mu \mathrm{mol} / \mathrm{L}$. Intravenous pulses of methylprednisolone $500 \mathrm{mg}$ IV were given even though the rash already showed some improvement. Two days later, the creatinine level decreased to $457 \mu \mathrm{mol} / \mathrm{L}$. Prednisone $100 \mathrm{mg}$ daily was given for seven days, followed by prednisone $50 \mathrm{mg}$ daily for one week with a $5 \mathrm{mg}$ decrease each week until complete discontinuation. At discharge, on January $16^{\text {th }}$, the creatinine level was down to $171 \mu \mathrm{mol} / \mathrm{L}$, the eosinophils count was $600 \mathrm{~mm}^{3}$ and the rash showed complete resolution.

Unfortunately, the patient had a relapse of his diffuse rash at the end of January while the prednisone was at $40 \mathrm{mg}$ daily (Figure 1). Serum creatinine level was then $130 \mu \mathrm{mol} / \mathrm{L}$. Since DRESS syndrome is known to last longer than other drug related skin reaction, it was probably still the reaction from levetiracetam but phenytoin being one of the more typical drug associated with DRESS, it was changed to valproate. The skin rash slowly

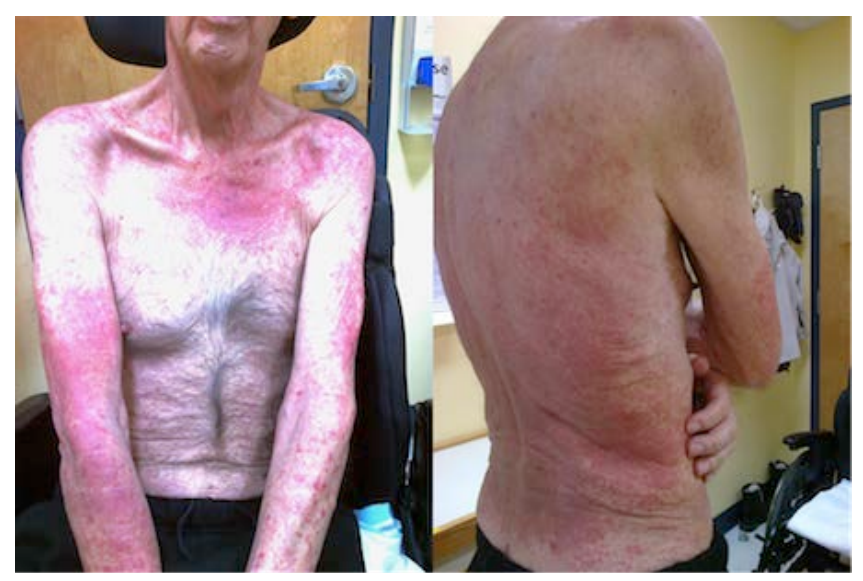

Figure 1. Rash on patient's thorax and arms (left panel) and back (right panel). 
resolved and the last creatinine level was $88 \mu \mathrm{mol} / \mathrm{L}$ in July 2014. No further episode of skin rash or acute kidney injury was noted. Sadly, the patient suffered a relapsed from his brain cancer and is now in palliative care.

\section{Discussion}

A diagnosis of DRESS syndrome should be suspected in a patient with a new drug exposure who develops a skin eruption, eosinophilia or atypical lymphocytosis and systemic involvement like interstitial nephritis, but also hepatitis, pneumonitis or myocarditis.

Presentation typically occurs two to eight weeks after initiation of the offending agent. The presence of dexamethasone could explain the longer delay (10 weeks) in our case. A definite proof of drug reaction requires rechallenge after resolution of the disease. In severe reactions such as this one, it would be unethical to do so, we must thus work with probability linked to chronology.

Aromatic antiepileptic drugs and allopurinol are the most frequently reported culprits [1]. Non-aromatic antiepileptic drugs such as levetiracetam were initially thought to be safe, but at least three cases of DRESS syndrome in patients taking this substance were reported [3] [4], none included renal involvement. Renal involvement is rare in the literature, except for allopurinol that causes renal dysfunction in $84 \%$ of the cases in the literature and $43 \%$ of the cases reported in the French Pharmacovigilance Database [6]. We herein describe, to the best of our knowledge, the first case of a DRESS with renal involvement caused by levetiracetam. We presume this kidney impairment to be an acute interstitial nephritis but no kidney biopsy was deemed necessary to start treatment with corticosteroids.

The pathophysiology of DRESS syndrome is not well described. Part of it seems to include herpes virus reactivation [7] and expansion of activated T lymphocytes, but there is no clear evidence if the drug reaction is the primary trigger or an amplificater of a subclinical viral infection [8] [9]. Links have been found mainly with HHV-6, but also in HHV-7 and EBV reactivation [9]. To our knowledge, HSV-1 reactivation has not been reported in DRESS syndrome. In this case, serology for HHV-6 was not performed.

The European Registry of Severe Cutaneous Adverse Reactions (RegiSCAR) proposed a score in 2007 to help clinicians in confirming or excluding the diagnosis of DRESS [10]. The criteria of this system are: fever greater than $38.5^{\circ} \mathrm{C}$; enlarged lymph nodes; eosinophilia; atypical lymphocytosis; skin involvement; organ involvement; resolution greater than 15 days; and evaluation of other potential causes (ANA, blood cultures, serology for hepatitis A virus, hepatitis B virus, hepatitis C virus, chlamydia and/or mycoplasma or other appropriate serology). With this score, more than five points indicates a definite case. Our patient had a calculated score of six points indicating a definite diagnostic: 2 for the eosinophilia, 2 for the skin involvement, 1 for enlarged lymph nodes, 1 for kidney involvement, 1 for other potential cause, -1 for fever not $\geq 38.5^{\circ} \mathrm{C}$ (it was $38.2^{\circ} \mathrm{C}$ ).

Prompt identification and discontinuation of the offending drug is the mainstay of the management. Once done, the rash and the organ involvement usually resolve gradually between six or nine weeks, but about 20 percent of the patients experience persistence of symptoms with remissions and relapses of the syndrome [11]. No treatment has been evaluated in randomized trials but it is generally accepted that patients with severe organ involvement should be treated with systemic corticosteroids on the basis of case reports and retrospective studies. The French Society of Dermatology published in 2010 a consensus on therapeutic management of the syndrome [12]. The recommendation was to treat patients with any signs of severity, including renal involvement, with systemic steroid equivalent to one $\mathrm{mg} / \mathrm{kg} /$ day of prednisolone. Use of intravenous immunoglobulin (IVIG) at two $\mathrm{g} / \mathrm{kg}$ over five days for life-threatening situation including kidney failure was also part of the recommendation, but benefits of IVIG remain controversial with the publication of newest articles showing contradictory results [13] [14]. The last recommendation of that consensus is to combine ganciclovir to steroid in severe cases with confirmation of a major viral reactivation of HHV-6.

\section{Conclusion}

This first case of acute kidney injury in a DRESS syndrome following introduction of levetiracetam confirms this antiepileptic drug as a rare cause of potentially severe acute renal insufficiency.

\section{Acknowledgements}

We thank Tanya Fayad for her thorough review of the manuscript and helpful advices. 


\section{Conflict of Interest Statement}

None to declare.

\section{References}

[1] Kardaun, S.H., Sekula, P., Valeyrie-Allanore, L., et al. (2013) Drug Reaction with Eosinophilia and Systemic Symptoms (DRESS): An Original Multisystem Adverse Drug Reaction. Results from the Prospective RegiSCAR Study. British Journal of Dermatology, 169, 1071-1080. http://dx.doi.org/10.1111/bjd.12501

[2] Chen, Y.C., Chui, H.C. and Chu, C.Y. (2010) Drug Reaction with Eosinophilia and Systemic Symptoms: A Retrospective Study of 60 Cases. Archives of Dermatology, 146, 1373-1379. http://dx.doi.org/10.1001/archdermatol.2010.198

[3] Hall, D.J. and Fromm, J.S. (2013) Drug Reaction with Eosinophilia and Systemic Symptoms Syndrome in a Patient Taking Phenytoin and Levetiracetam: A Case Report. Journal of Medical Case Reports, 7, 2. http://dx.doi.org/10.1186/1752-1947-7-2

[4] Gomez-Zorrilla, S., Ferraz, A.V., Pedros, C., Lemus, M. and Pena, C. (2012) Levetiracetam-Induced Drug Reaction with Eosinophilia and Systemic Symptoms Syndrome. Annals of Pharmacotherapy, 46, e20. http://dx.doi.org/10.1345/aph.1R084

[5] Mahta, A., Kim, R. and Kesari, S. (2012) Levetiracetam-Induced Interstitial Nephritis in a Patient with Glioma. Journal of Clinical Neuroscience, 19, 177-178. http://dx.doi.org/10.1016/j.jocn.2011.08.007

[6] Peyrière, H., Dereure, O., Breton, H., et al. (2006) Variability in the Clinical Pattern of Cutaneous Side-Effects of Drugs with Systemic Symptoms: Does a DRESS Syndrome Really Exist? British Journal of Dermatology, 155, 422428. http://dx.doi.org/10.1111/j.1365-2133.2006.07284.x

[7] Descamps, V., Valance, A., Edlinger, C., et al. (2001) Association of Human Herpesvirus 6 Infection with Drug Reaction with Eosinophilia and Systemic Symptoms. Archives of Dermatology, 137, 301-304.

[8] Takahashi, R., Kano, Y., Yamazaki, Y., Mizukawa, Y. and Shiohara, T. (2009) Defective Regulatory T Cells in Patients with Severe Drug Eruptions: Timing of the Dysfunction Is Associated with the Pathological Phenotype and Outcome. Journal of Immunology, 182, 8071-8079. http://dx.doi.org/10.4049/jimmunol.0804002

[9] Picard, D., Janela, B., Descamps, V., et al. (2010) Drug Reaction with Eosinophilia and Systemic Symptoms (DRESS): A Multiorgan Antiviral T Cell Response. Science Translational Medicine, 2, 46-62. http://dx.doi.org/10.1126/scitranslmed.3001116

[10] Kardaun, S.H., Sidoroff, A., Valeyrie-Allanore, L., et al. (2007) Variability in the Clinical Pattern of Cutaneous SideEffects of Drugs with Systemic Symptoms: Does a DRESS Syndrome Really Exist? British Journal of Dermatology, 156, 609-611. http://dx.doi.org/10.1111/j.1365-2133.2006.07704.x

[11] Cacoub, P., Musette, P., Descamps, V., et al. (2011) The DRESS Syndrome: A Literature Review. The American Journal of Medicine, 124, 588-597. http://dx.doi.org/10.1016/j.amjmed.2011.01.017

[12] Descamps, V., Ben-Saïd, B., Sassolas, B., et al. (2010) Management of Drug Reaction with Eosinophilia and Systemic Symptoms (DRESS). Annales de Dermatologie et de Vénéréologie, 137, 703-708. http://dx.doi.org/10.1016/j.annder.2010.04.024

[13] Joly, P., Janela, B., Tetart, F., et al. (2012) Poor Benefit/Risk Balance of Intravenous Immunoglobulins in DRESS. Archives of Dermatology, 148, 543-544.

[14] Singer, E.M., Wanat, K.A. and Rosenbach, M.A. (2013) A Case of Recalcitrant DRESS Syndrome with Multiple Autoimmune Sequelae Treated with Intravenous Immunoglobulins. JAMA Dermatology, 149, 494-495. http://dx.doi.org/10.1001/jamadermatol.2013.1949 
Scientific Research Publishing (SCIRP) is one of the largest Open Access journal publishers. It is currently publishing more than 200 open access, online, peer-reviewed journals covering a wide range of academic disciplines. SCIRP serves the worldwide academic communities and contributes to the progress and application of science with its publication.

Other selected journals from SCIRP are listed as below. Submit your manuscript to us via either submit@scirp.org or Online Submission Portal.
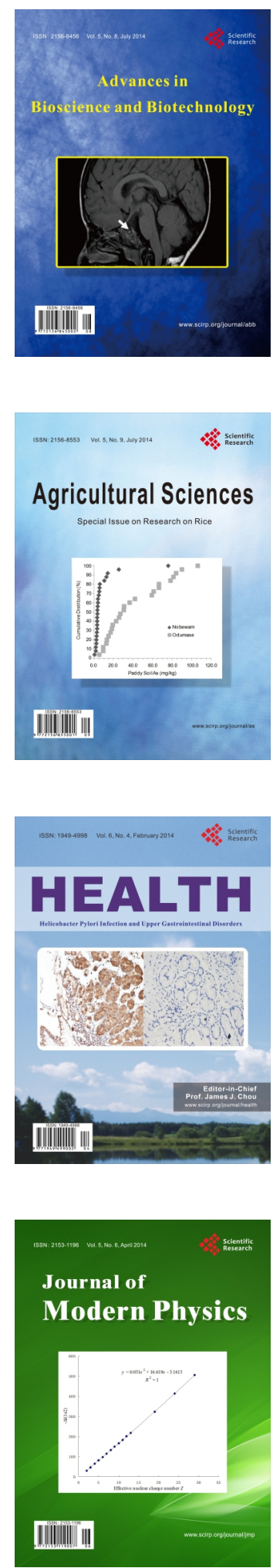
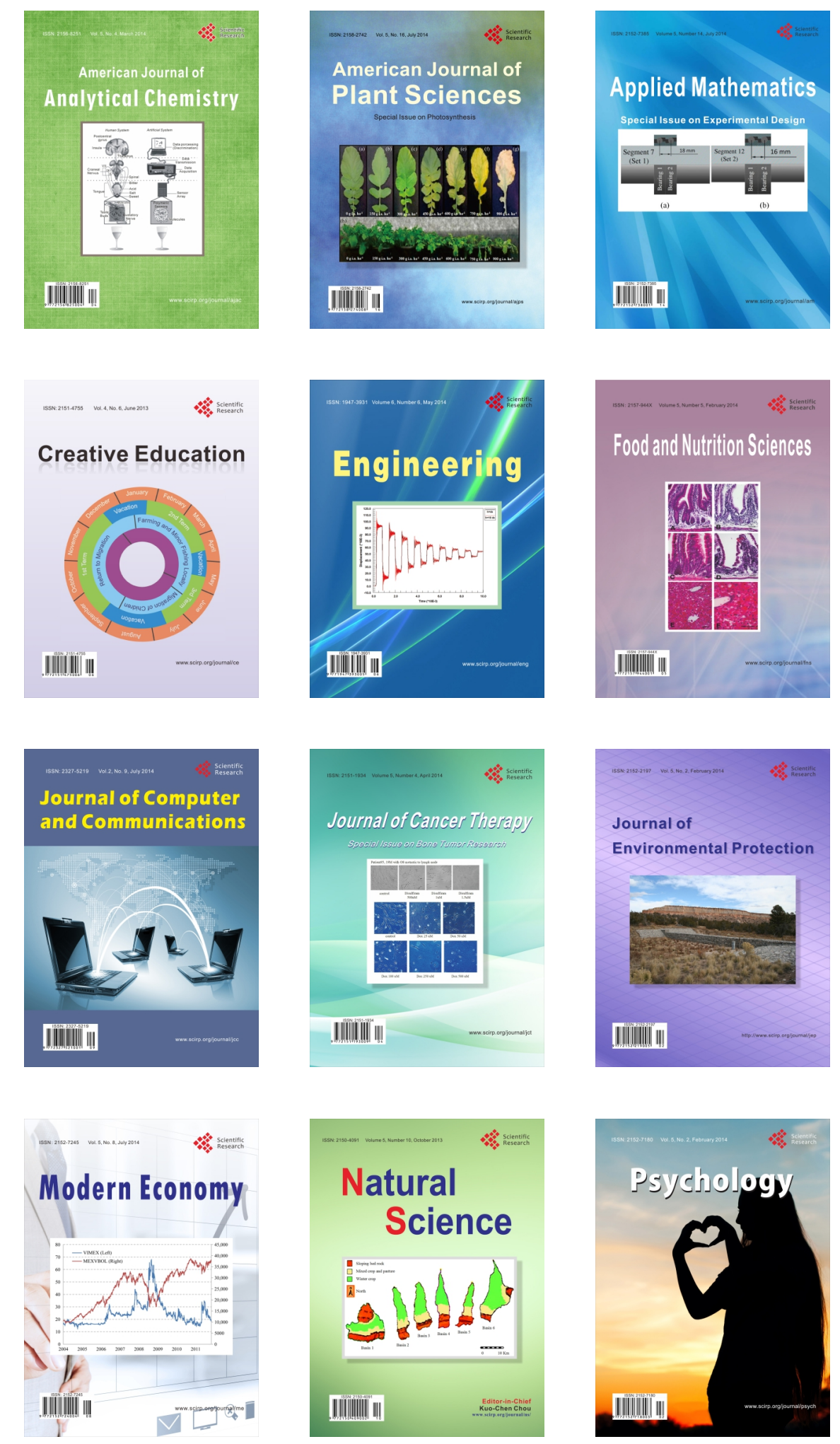